\title{
Academic socialization of children in tea communities of Assam
}

\author{
Poppy Gogoi, Tulika Borah and Sampreety Gogoi
}

Received: 08.07.2019; Revised: 17.10.2019; Accepted: 01.11.2019

See end of the paper for authors' affiliations Poppy Gogoi

Department of Human Development and Family Studies, College of Community Science, Assam Agricultural University, Jorhat (Assam) India Email : poppygogoi94@gmail. com
ABSTRACT : Academic socialization is a way to facilitate the educational development of children by involving in school related and other academics activities of children. Parents are considered to be the primary agents of child socialization. Hence, parent's beliefs and behaviors regarding school-related activities influence children's academic performance. The present study was an attempt to assess the academic socialization provided by parents to their children in tea communities of Assam. The sample consisted of 100 parents who had children studying in either lower primary or secondary school standards. From the total 100 samples, 50 respondents having girl child and 50 respondents having boy were selected. Samples were selected on the basis of stratified random sampling from the tea gardens of Jorhat district of Assam. An interview schedule was used for data collection. The result revealed that majority of the respondents provide medium level of academic socialization to their children and academic socialization provided to children studying in lower primary standards was found to be better than children studying in secondary standards.

KEY WORDS: Academic socialization, Lower primary class, Secondary class

- HOW TO CITE THIS PAPER : Gogoi, Poppy, Borah, Tulika and Gogoi, Sampreety (2019). Academic socialization of children in tea communities of Assam. Asian J. Home Sci., 14 (2) : 338-340, DOI: 10.15740/ HAS/AJHS/14.2/338-340. Copyright@ 2019: Hind Agri-Horticultural Society. 